\title{
Editorial TS: Papers from the 3rd Luso-Brazilian Conference on Adhesion and Adhesives (CLBA2016), Rio de Janeiro, Brazil, 25-27 January 2016
}

\author{
Lucas F. M. da Silva ${ }^{1 *}$ and Silvio de Barros²
}

${ }^{*}$ Correspondence: lucas@fe.up.pt

${ }^{1}$ Departamento de Engenharia Mecânica,

Faculdade de Engenharia da Universidade do Porto,

Rua Dr. Roberto Frias,

4200-465 Porto, Portugal

Full list of author information

is available at the end of the

article
This special issue of Applied Adhesion Science (AAS) contains selected papers presented at the 3rd Luso-Brazilian Conference on Adhesion and Adhesives (CLBA 2016) held in Rio de Janeiro, Brazil, during January 25-27, 2016. CLBA 2016 was chaired by both of us and was co-organized by the Brazilian Association of Adhesion and Adhesives (ABAA) and the Portuguese Association of Adhesion and Adhesives (APAA). The goal of the conference was to join the Portuguese and Brazilian communities to discuss issues related to adhesive bonding research lately developed in both countries. Approximately 60 papers were presented by researchers from many universities and research centers. In order to disseminate the work presented at CLBA 2016, selected papers were prepared which resulted in the present Special Issue.

Four papers deal with adhesive dentistry aspects. They were presented by colleagues from the Brazilian dental materials community. Lopes et al. evaluated the influence of the previous use of eugenol based materials to a permanent restoration on the marginal microleakage. They also investigated the influence of mechanical cleansing associated with chemical cleansing with chlorhexidine gel. It was found that eugenol, when associated with endodontic or temporary restorative material, has no influence on the microleakage of the definitive composite resin restoration. The study presented by Da Silva et al. evaluated the shear bond strength of three different composite resins to fiber posts surfaces. The influence the adhesive used as pretreatment was also investigated. The authors concluded that the use of silorane based composite resins to customize posts requires the use of adhesive as surface pretreatment. Schwertner et al. evaluated the effect of green tea on the shear bond strength of metal orthodontic brackets to human enamel after home whitening treatment. They concluded that green tea is an alternative treatment to allow bracket bonding immediately after home whitening treatment. Another study on the shear bond strength of brackets to enamel was presented by Guiraldo et al. The objective of the study was to evaluate the enamel roughness and shear bond strength of dental composite after removal of metal brackets bonded with different adhesives. The shear bond test results shown that the 4 adhesives produced adequate bond strength, however the enamel did not return to the initial conditions.

c) The Author(s) 2017. This article is distributed under the terms of the Creative Commons Attribution 4.0 International License (http://creativecommons.org/licenses/by/4.0/), which permits unrestricted use, distribution, and reproduction in any medium, provided you give appropriate credit to the original author(s) and the source, provide a link to the Creative Commons license, and indicate if changes were made. 
Two papers focus on the use of castor oil polyurethane as adhesive applied to different substrates. Pareira et al. performed shear tests using MDF substrates. They concluded that the polyurethane derived from castor oil can be used to bind MDF panels. The results show its superior shear average resistance compared to a synthetic adhesive. Mölleken et al. evaluated the pressing time in the production of Pinus taeda edge glued panels (EGP). According to their results the optimal pressing time for the panels production is $4 \mathrm{~h}$.

The review process gave a deeper insight into the last developments in adhesion in Brazil and Portugal and the chance to discuss in detail the manuscripts directly with the authors. We would like to thank the authors for their patience with the process and the reviewers for providing critical evaluations of these manuscripts. This special issue was sponsored by the Brazilian Federal Agency for the Support and Evaluation of Graduate Education (CAPES).

Author details

${ }^{1}$ Departamento de Engenharia Mecânica, Faculdade de Engenharia da Universidade do Porto, Rua Dr. Roberto Frias, 4200-465 Porto, Portugal. ${ }^{2}$ Department of Mechanical Engineering, Federal Center of Technological Education (CEFET/ RJ), Av. Maracanã 229, Rio de Janeiro, RJ 20271-110, Brazil.

\section{Publisher's Note}

Springer Nature remains neutral with regard to jurisdictional claims in published maps and institutional affiliations.

Received: 6 June 2017 Accepted: 15 June 2017

Published online: 23 June 2017

\section{Submit your manuscript to a SpringerOpen ${ }^{\mathcal{O}}$} journal and benefit from:

- Convenient online submission

- Rigorous peer review

- Open access: articles freely available online

- High visibility within the field

Retaining the copyright to your article

Submit your next manuscript at $\boldsymbol{\Delta}$ springeropen.com 